\title{
Trial Paths Supplemental Qualifiers Dataset
}

National Cancer Institute

\section{Source}

National Cancer Institute. Trial Paths Supplemental Qualifiers Dataset. NCI Thesaurus. Code $C 147260$.

A dataset containing supplemental information, specifically non-standard variables, to parent records in the trial paths domain. 